\title{
Short burst oxygen therapy after activities of daily living in the home in chronic obstructive pulmonary disease
}

\author{
S J Quantrill, R White, A Crawford, J S Barry, S Batra, P Whyte, C M Roberts
}

Thorax 2007;62:702-705. doi: 10.1136/thx.2006.063636

See end of article for authors' affiliations

\section{Correspondence to:}

Dr S J Quantrill, Chest Clinic, Whipps Cross University Hospital, London E11 INR, UK; simon.quantrill@

whippsx.nhs.uk

Received 7 April 2006

Accepted 24 January 2007

Published Online First

20 February 2007
Background: Short burst oxygen therapy (SBOT) is widely prescribed in the UK with little evidence of benefit. A study was performed to examine whether SBOT benefits patients when undertaking normal activities at home among those who already use it.

Methods: Twenty-two patients with chronic obstructive pulmonary disease (COPD) were included in the study. All regularly used SBOT at home and claimed that it helps them. Each patient chose two daily living activities for which they used SBOT for relief of breathlessness. Patients were then randomised to use either an air or oxygen gas cylinder. At least 15 min later the same activity was performed using the other gas cylinder. The same process was then repeated for the second chosen activity. The main endpoints were subjective and objective times to recovery, analysed for each activity separately or taking the average over the two activities. A paired statistical analysis was performed.

Results: All patients used SBOT with nasal prongs after exercise. Using the average recovery time over two activities for each patient, the mean objective recovery time was 38 s lower $(95 \% \mathrm{Cl}-81$ to +5$)$ using oxygen and the mean subjective recovery time was $34 \mathrm{~s}$ lower $(95 \% \mathrm{Cl}-69$ to +2$)$. Five patients were correctly able to distinguish oxygen from air after both activities and there was a suggestion that their recovery times were shorter than those who did not correctly identify the gases $(91$ s vs 20 s using objective recovery times, and $80 \mathrm{~s}$ vs $22 \mathrm{~s}$ using subjective recovery times), although this was a subgroup analysis based on only five patients with non-significant results.

Conclusions: There is some evidence that SBOT shortens recovery time after activities of daily living in a selected group of patients with COPD, but the effect is small. There appears to be a subgroup of patients who may benefit to a much greater degree.
$\mathrm{S}$ hort burst oxygen therapy (SBOT) refers to the intermittent use of oxygen, usually from a static cylinder. It is widely prescribed for the alleviation of breathlessness in patients with chronic obstructive pulmonary disease (COPD), despite little convincing evidence of benefit. ${ }^{1}$ In the UK nearly $£ 18$ million was spent on oxygen cylinders in the year 2004-5, and the cost has risen annually since $1997 .{ }^{2}$ International COPD guidelines do not offer any concrete recommendations on who should receive SBOT and when to prescribe it, ${ }^{3-7}$ in contrast to long-term oxygen therapy (LTOT) via a concentrator and ambulatory oxygen with a portable cylinder, both of which have been proved to be effective..$^{8-10}$ The continued use of SBOT may be a reflection of the lack of conclusive studies and anecdotal reports of benefit from patients. Studies published to date have all been conducted in the hospital or laboratory setting, often requiring the patient to undertake activities with which they may be unfamiliar such as cycling and treadmill tests. ${ }^{11}{ }^{12}$

We aimed to determine whether patients who claimed that they were helped by SBOT and were using it regularly at home could demonstrate consistent subjective and objective benefit likely to be of clinical value. Our aims were confined to determining benefit from using SBOT for exercise, and not from other uses such as breathlessness at rest and during or recovering from exacerbations.

\section{METHODS \\ Subjects}

Thirty-nine patients with COPD defined by NICE criteria ${ }^{3}$ who regularly used SBOT at home were identified from the Waltham Forest general practice prescribing database and screened using a telephone questionnaire to ascertain suitability for the study.
It was a specific requirement that all patients reported that oxygen use was of value in reducing the symptom of breathlessness and had replaced their oxygen cylinder at least once in the past 6 months, as an indication of current usage. Patients with significant comorbidity causing limitation of exercise were excluded, as were patients who stated that they did not benefit from oxygen or who had not replaced their cylinder within the past 6 months. Patients were required to be in a stable clinical state and at least 6 weeks free from an acute exacerbation when visited at home. Informed written consent was obtained and the study was approved by the Waltham Forest ethics committee.

\section{Tests of activities of daily living}

Patients were asked to name two activities of daily living such as walking upstairs or vacuum cleaning for which they might normally use their SBOT, and how they would normally use their oxygen to relieve breathlessness (eg, nasal prongs or mask, before or after exercise). Each subject was studied at home performing each of their self-selected daily living activities and received either compressed air from a cylinder or oxygen from a cylinder in a randomised blinded fashion. Patients received either oxygen or air first and then crossed over to use the other cylinder after a minimum rest period of $15 \mathrm{~min}$. Each patient did the two different activities twice (once recovering with air and once with oxygen), making a total of 88 separate activities. Cylinders were labelled "gas A" and "gas

Abbreviations: COPD, chronic obstructive pulmonary disease; $\mathrm{FEV}_{1}$, forced expiratory volume in $1 \mathrm{~s}$; LTOT, long-term oxygen therapy; SBOT, short burst oxygen therapy; TLCO, carbon monoxide transfer factor; VAS, visual analogue score 
$\mathrm{B}^{\prime \prime}$ and were blinded to both patients and researchers. Patients performed each activity until they felt the need to stop and use oxygen. Subsequent tests were only performed when the patient had completely recovered from the previous activity, both subjectively and objectively. Pulse oximetry (Minolta Pulsox 3iA, Sunrise Medical, UK) was monitored throughout.

Endpoint measures were subjective and objective recovery times. Subjective recovery was defined as the point at which each patient stated their breathing had returned to normal. Objective recovery was defined as occurring when the oxygen saturation had returned to within $2 \%$ and heart rate to within 5 beats/min of pre-activity values. Breathlessness was measured using a $10 \mathrm{~cm}$ visual analogue score (VAS) with the end points of "not breathless at all" and "the most breathless I have ever been" at the start and end of each activity and at the point of subjective recovery. After each activity had been repeated, patients were asked if one cylinder enabled them to recover quicker than the other. If they did notice a difference, they were asked if the less effective cylinder was "better than nothing at all".

\section{Statistical analysis}

The recovery time for each patient was taken as the average time for the two activities undertaken. Recovery times tended to have a skewed distribution (long tail to the right), so both the mean and median values are presented. However, the differences in recovery times (oxygen minus air) tended to be normally distributed (as determined by a probability plot) so paired $t$ tests were used. Data were analysed using SPSS. The sample size was originally estimated to be 20 patients based on differences in VAS measurements for breathlessness to detect a difference of $8 \mathrm{~mm}$ with $90 \%$ power. However, VAS measurements would only have been useful for patients using SBOT before exercise, and during the course of the study we discovered that all patients used it after exercise. We therefore considered recovery times to be more appropriate, but it was difficult to perform a power calculation at the outset when the range of recovery times and expected differences between the groups was not known and could not be anticipated from existing data.

\section{RESULTS}

\section{Patient characteristics}

Twenty-two patients ( 14 men, mean age 72 years, range 56-86) were deemed suitable and agreed to take part. Reasons for exclusion among the other 17 patients included comorbidity $(n=6)$, SBOT not used in relation to exertion $(n=6)$, current exacerbation $(n=2)$, too unwell $(n=1)$, away from home $(n=1)$, and SBOT not yet prescribed $(n=1)$. The characteristics of patients included in the study are shown in table 1 .

Seventeen patients had moderate or severe COPD as measured by spirometry but, although forced expiratory volume in $1 \mathrm{~s}\left(\mathrm{FEV}_{1}\right)$ in the remaining five patients was $>50 \%$ predicted, carbon monoxide transfer factor (TLCO) in four of these five patients was $<42 \%$ predicted indicating significant emphysema (unmeasured in the other). Most desaturated on exercise. Eleven patients (50\%) used LTOT via a concentrator.

Table 1 Characteristics of subjects $(n=22)$

\begin{tabular}{lll}
\hline & Mean (SD) & Range \\
\hline Age (years) & $72.0(7.3)$ & $56-86$ \\
$\mathrm{FEV}_{1}$ (litres) & $0.87(0.38)$ & $0.40-1.69$ \\
$\mathrm{FEV}_{1}(\%$ predicted) & $38.0(16.1)$ & $17-74$ \\
$\mathrm{SaO}_{2}(\%)$ resting, on air & $93.1(3.8)$ & $82-98$ \\
Desaturation with activity (\%) & -7.5 & -25 to -0.5
\end{tabular}

$\mathrm{FEV}_{1}$, forced expiratory volume in $1 \mathrm{~s} ; \mathrm{SaO}_{2}$, oxygen saturation.
All patients stated that they breathed oxygen via nasal prongs and none used masks. Flow rates were $2 \mathrm{l} / \mathrm{min}$ in 18 patients and $4 \mathrm{l} / \mathrm{min}$ in 4 . In addition, all used their oxygen after activity and none before activity. Activities selected by patients for use of oxygen included walking upstairs $(n=20)$, walking around the house or garden $(n=13)$, vacuum cleaning $(n=8)$, walking uphill $(\mathrm{n}=1)$, kitchen work $(\mathrm{n}=1)$ and sweeping up $(\mathrm{n}=1)$. Activity time and change in VAS after activity was not significantly different between oxygen and air.

\section{Duration of activity}

Because the same activity was performed twice (once with oxygen and once with air), we checked that the length of activity was similar when using oxygen or air in case this could explain the differences in recovery times. There was no evidence that activity length differed. During the first activity the mean difference in the length of activity (oxygen minus air) was $-8 \mathrm{~s}(\mathrm{p}=0.64$, paired $t$ test $)$, and during the second chosen activity the mean difference was $11 \mathrm{~s}(\mathrm{p}=0.60)$.

\section{Recovery time}

Subjective and objective times to recovery with oxygen and air are shown in table 2. The table shows the effect of oxygen therapy for each activity separately and the mean of the two activities. There was no difference in recovery times with oxygen compared with air. There was, however, a tendency for the effect on objective recovery times to be greater during the first activity (table 2). This may not be surprising given that, by the time the patient performed the second activity, he/she would already have performed the first activity twice.

\section{Ability to distinguish oxygen from air}

Five patients $(22.7 \%)$ were correctly able to distinguish the oxygen from air on both occasions, five were able to identify the oxygen after one activity only, and 10 could not identify the oxygen on either occasion. Seven patients thought that, even though they had identified one gas as not being oxygen, it was better than nothing at all. Data were not available for two patients. A subgroup analysis was performed on the five patients who correctly distinguished oxygen from air on both occasions and the results were compared against those who could not. This subgroup of five correct identifiers had shorter subjective and objective recovery times using oxygen compared with air (80 s and 91 s, respectively, vs $22 \mathrm{~s}$ and $20 \mathrm{~s}$ for incorrect identifiers), although these results did not reach statistical significance (fig 1).

There were no significant differences in age, \% predicted $\mathrm{FEV}_{1}$, baseline oxygen saturation or mean lowest desaturation between the two subgroups. There was no significant difference in either objective recovery time $(p=0.77)$ or subjective recovery time $(p=0.13)$ for those patients on LTOT compared with those who were not.

\section{DISCUSSION}

The data in this study suggest that SBOT shortens recovery time after activities of daily living in a highly selected group of patients with COPD. However, the beneficial effect is small overall. The shortening of recovery times did not reach statistical significance, but this is likely to be due to the relatively small number of subjects. One of the limitations of the study was that sample size was powered on a different outcome measure (VAS score) which was subsequently found to be inappropriate for this particular study. To show a difference in recovery times of about $35 \mathrm{~s}$ would require at least 50 patients (paired analysis), more than twice as many as the current study. 
Table 2 Comparison of the effect of oxygen therapy and air on recovery times

\begin{tabular}{|c|c|c|c|c|c|c|c|c|}
\hline & \multicolumn{3}{|c|}{ Recovery time with oxygen (s) } & \multicolumn{3}{|c|}{ Recovery time with air (s) } & \multirow{2}{*}{$\begin{array}{l}\text { Mean difference } \\
\text { (oxygen minus air) } \\
(95 \% \mathrm{CI})\end{array}$} & \multirow[b]{2}{*}{ p Value } \\
\hline & Median & IQR & Mean & Median & IQR & Mean & & \\
\hline \multicolumn{9}{|l|}{ Activity 1} \\
\hline Objective & 65 & 55 & 90 & 120 & 95 & 145 & $-55(-115$ to +5$)$ & 0.07 \\
\hline Subjective & 170 & 98 & 169 & 165 & 160 & 201 & $-32(-85$ to +20$)$ & 0.21 \\
\hline \multicolumn{9}{|l|}{ Activity 2} \\
\hline Objective & 58 & 78 & 104 & 110 & 120 & 129 & $-25(-96$ to +47$)$ & 0.48 \\
\hline Subjective & 180 & 120 & 207 & 230 & 150 & 241 & $-35(-76$ to +6$)$ & 0.09 \\
\hline \multicolumn{9}{|c|}{$\begin{array}{l}\text { Mean of activities } 1 \\
\text { and } 2\end{array}$} \\
\hline Objective & 75 & 82 & 97 & 110 & 62 & 135 & $-38(-81$ to +5$)$ & 0.08 \\
\hline Subjective & 186 & 110 & 186 & 240 & 140 & 219 & $-34(-69$ to +2$)$ & 0.06 \\
\hline
\end{tabular}

$I Q R$, interquartile range.

Previous studies have shown similar small improvements with SBOT or no benefit overall for the alleviation of breathlessness on exertion in COPD. ${ }^{11}{ }^{12}{ }^{13-17}$ There may, however, be concerns that these trials have missed a subgroup of patients for whom SBOT is beneficial. In our study only 5 of 20 patients questioned were correctly able to distinguish oxygen from air after both sets of activities, a finding which is even more striking considering that all our patients had claimed that SBOT helped them in undertaking these activities. However, there was a much greater difference in recovery time for the 5 patients who correctly distinguished oxygen from air both times (80 s for subjective recovery and $91 \mathrm{~s}$ for objective
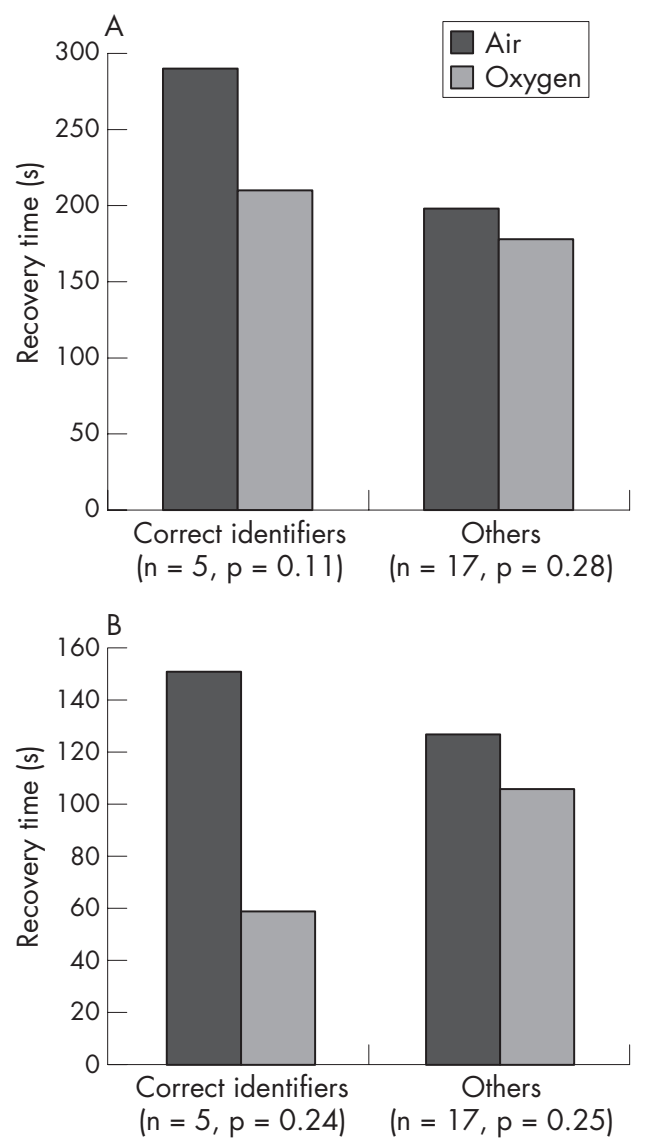

Figure 1 (A) Subjective time to recovery and (B) objective time to recovery in subgroup who correctly identified oxygen after both activities $(n=5)$ and those who did not $(n=17)$. recovery) and, although not statistically significant, this could represent a subgroup for which oxygen is beneficial.

Previous studies have all been conducted in the artificial setting of the lung function laboratory or hospital environment and have studied a mixture of patients who may or may not be regular oxygen users. ${ }^{11}{ }^{12}{ }^{13-17}$ Our study is unique as we aimed to overcome these problems by specifically targeting the subgroup that regularly use SBOT, testing patients at home undertaking activities of daily living with which they are familiar. Furthermore, it was a specific requirement that patients claimed SBOT alleviated their breathlessness. Interestingly, all our patients used oxygen after the activity and none before, suggesting that they do not perceive benefit from pre-oxygenating. This concurs with the results of studies in which patients were administered oxygen before exercise. ${ }^{131516}$

The difficult question of when a change becomes clinically significant in terms of relief of breathlessness, shortening of recovery time and improvement of exercise capacity can be illustrated by the wide variation in cut-off points used in studies of SBOT and ambulatory oxygen. ${ }^{12}{ }^{15}$ 17-22 Although the subjective recovery time was $34 \mathrm{~s}$ or $15 \%$ shorter with oxygen than with compressed air, the clinical importance of this must be debatable. McDonald et al, ${ }^{23}$ in a study of ambulatory oxygen in COPD, also make the point that the increase in 6 minute walking distance of $<20 \mathrm{~m}$ in their laboratory tests, while of "statistical significance", did not translate into any useful improvement in day-to-day functioning and the prescription of oxygen on the basis of these tests could not therefore be justified. Perhaps we should move away from a statistical model of what is significant to a more patient-centred view, reflecting the change in philosophy of the UK healthcare system as a whole over recent years.

The limitations of our study are the relatively small numbers included which means that a statistically significant reduction in overall objective recovery time could have been missed, but there is still the question of whether this would be of any clinical value. Our study also included a mixture of patients, half of whom were receiving LTOT. However, this simply reflects actual clinical practice where SBOT is prescribed. Some patients with a concentrator used this at times instead of a cylinder (although not in the study); however, they were all known to use their oxygen cylinder regularly as this is how they were originally identified from prescribing records. All patients used nasal prongs, which is a possible confounder as some who are predominantly mouth breathers might benefit more from oxygen via a mask. We did not study the effect of SBOT during exacerbations which is another important area for research, particularly as oxygen cylinder usage may increase at these 
times and also be prescribed for patients on discharge from hospital.

In conclusion, we have shown that SBOT does appear to shorten recovery time overall after activities of daily living in this highly selected patient group, but it is debatable whether this is of clinical significance. However, there appears to be a small subgroup of patients who are able to perceive this benefit, and a larger study is needed to verify this and determine how they may be identified.

\section{Authors' affiliations}

S J Quantrill, R White, A Crawford, J S Barry, P Whyte, S Batra,

C M Roberts, Whipps Cross University Hospital, London, UK

Funding: Chest Clinic Amenity Fund.

Competing interests: None declared.

\section{REFERENCES}

1 Roberts CM. Short burst oxygen therapy for relief of breathlessness in COPD. Thorax 2004:59:638-40.

2 Prescription Pricing Authority. www.ppa.org.uk/pdfs/ PPA_stakeholder_review_2004-2005.pdf (accessed 6 April 2006)

3 National Collaborating Centre for Chronic Conditions. National clinical guideline on management of chronic obstructive pulmonary disease in adults in primary and secondary care. Thorax, 2004;59(Suppl 1).

4 American Thoracic Society. Standards for the diagnosis and care of patients with chronic obstructive pulmonary disease. Am J Respir Crit Care Med 1995; 152:S77-121.

5 Siafakas NM, Vermeire P, Pride NB, et al. Optimal assessment and management of chronic obstructive pulmonary disease (COPD). The European Respiratory Society Task Force. Eur Respir J 1995;8:1398-420.

6 National Heart Lung Blood Institute. WHO. Global initiative for chronic obstructive lung disease: global strategy for diagnosis, management, and prevention of chronic obstructive pulmonary disease, 2005.www.goldcopd.com/ Guidelineitem.asp? 1 = 2\&l2 = 1 \&intld = 989 (accessed 6 April 2006).

7 Pauwels RA, Buist SA, Calverley PM, et al. Global strategy for the diagnosis, management, and prevention of chronic obstructive pulmonary disease, $\mathrm{NHLBI} /$
WHO Global Initiative for Chronic Obstructive Lung Disease (GOLD) Workshop Summary.Am J Respir Crit Care Med, 2001;163:1256-76.

8 Nocturnal Oxygen Therapy Trial Group. Continuous or nocturnal oxygen therapy in hypoxemic chronic obstructive lung disease: a clinical trial. Ann Intern Med 1980;93:391-8.

9 Medical Research Council Working Party. Long term domiciliary oxygen therapy in chronic hypoxic cor pulmonale complicating chronic bronchitis and emphysema. Lancet 1981;1:681-6.

10 Davidson AC, Leach R, George RJ, et al. Supplemental oxygen and exercise ability in chronic obstructive airways disease. Thorax 1988;43:965-71.

11 Stevenson NJ, Calverley PM. Effect of oxygen on recovery from maximal exercise in patients with chronic obstructive pulmonary disease. Thorax 2004;59:668-72.

12 Woodcock AA, Gross ER, Geddes DM. Oxygen relieves breathlessness in "pink puffers". Lancet 1981;1:907-9.

13 Nandi K, Smith AA, Crawford A, et al. Oxygen supplementation before or after submaximal exercise in patients with chronic obstructive pulmonary disease. Thorax 2003:58:670-3.

14 Killen JW, Corris PA. A pragmatic assessment of the placement of oxygen when given for exercise induced dyspnoea. Thorax 2000;55:544-6

15 Lewis CA, Eaton TE, Young P, et al. Short-burst oxygen immediately before and after exercise is ineffective in nonhypoxic COPD patients. Eur Respir $J$ 2003;22:584-8.

16 McKeon JL, Murree-Allen K, Saunders NA. Effects of breathing supplemental oxygen before progressive exercise in patients with chronic obstructive lung disease. Thorax 1988;43:53-6.

17 Evans TW, Waterhouse JC, Carter A, et al. Short burst oxygen treatment for breathlessness in chronic obstructive airways disease. Thorax 1986;41:611-5.

18 Royal College of Physicians. Domiciliary oxygen therapy services. London: Royal College of Physicians, 1999

19 Wilson RC, Jones PW. Long-term reproducibility of Borg scale estimates of breathlessness during exercise. Clin Sci 1991;80:309-12.

20 Jolly EC, Di B, V, Aguirre L, et al. Effects of supplemental oxygen during activity in patients with advanced COPD without severe resting hypoxemia. Chest $2001 ; 120: 437-43$.

21 Leach RM, Davidson AC, Chinn S, et al. Portable liquid oxygen and exercise ability in severe respiratory disability. Thorax 1992;47:781-9.

22 Redelmeier DA, Bayoumi AM, Goldstein RS, et al. Interpreting small differences in functional status: the six minute walk test in chronic lung disease patients. Am J Respir Crit Care Med 1997:155:1278-82.

23 McDonald CF, Blyth CM, Lazarus MD, et al. Exertional oxygen of limited benefit in patients with chronic obstructive pulmonary disease and mild hypoxemia. Am J Respir Crit Care Med 1995;152:1616-9.

\section{bmjupdates+}

bmjupdates+ is a unique and free alerting service, designed to keep you up to date with the medical literature that is truly important to your practice.

bmjupdates+ will alert you to important new research and will provide you with the best new evidence concerning important advances in health care, tailored to your medical interests and time demands.

Where does the information come from?

bmjupdates+ applies an expert critical appraisal filter to over 100 top medical journals A panel of over 2000 physicians find the few 'must read' studies for each area of clinical interest

Sign up to receive your tailored email alerts, searching access and more...

www.bmjupdates.com 